\title{
UN MOT DU PREMIER MINISTRE
}

Le programme spécial du Canada en vertu duquel notre pays a accueilli 60,000 réfugiés indochinois en un peu plus d'un an et demi n'aurait pas été possible sans la participation de milliers de Canadiens d'un océan à l'autre.

Bien que le gouvernement précédent et celui que je dirige, de même que les provinces, aient tous appuyé le Programme d'aide aux réfugiés indochinois, son succès a néanmoins été assuré à la faveur de la participation totale et compatissante de milliers de Canadiens issus de tous les milieux.

Ce bulletin - mise en oeuvre par la Fondation canadienne pour les réfugiés et Operation Lifeline - est une autre initiative qui tombe à point. Il offrira un forum où l'on pourra recueillir informations et idées, et il contribuera à coordonner les services de groupes et d'agences bénévoles oeuvrant au bénéfice des réfugiés; sans doute encouragera-t-il également d'autres Canadiens à participer aux activités destinées à aider les réfugiés.

Le Canada continuera de faire sa juste part en faveur des réfugiés de toutes les régions de notre planète en proie à tant de difficultés. Je suis persuadé que ce bulletin deviendra un réseau de communications essentiel entre les gouvernements et les groupes de parrainage privés. Je félicite la Fondation canadienne pour les réfugiés et Operation Lifeline et leur offre mes meilleurs voeux à l'occasion de la publication de ce premier numéro.

\section{UNE TRAGÉDIE HUMAINE}

\section{par Linda Durno, directeur de "Relief and Development World Vision of Canada".}

Pendant que les Canadiens déployaient des efforts individuels et collectifs pour venir en aide aux réfugiés de la mer du Sud-Est asiatique, une autre tragédie humaine se jouait en sourdine dans la corne africaine où l'Éthiopie et la Somalie se disputent une région appelée Ogaden. Ce secteur se trouve dans les limites territoriales de l'Éthiopie, mais depuis des siècles, les tribus somaliennes nomades parcourent l'Ogaden à la recherche de pâturages pour leurs troupeaux dont dépend principalement leur subsistance.

Cette guerre, de même qu'une longue sécheresse et la famine ont poussé des milliers de nomades à fuir l'Ogaden pour aller dans le pays voisin, la Somalie. Considérés comme des réfugiés pour avoir droit à l'aide du HCNUR, ils sont maintenant 1,7 million. En Somalie, une personne sur quatre est un réfugié. Entassés dans 37 camps, ils constituent le plus important groupe de réfugiés au monde.

Je viens tout juste de visiter le camp de Las Dhure situé au Nord-Ouest de la Somalie. La souffrance et le désespoir de ces gens resteront longtemps gravés dans ma mémoire. Les Dhure, avec ses 76000 personnes, est le camp le plus important de la Somalie. Les conditions de vie y sont presque indescriptibles. De petits attels ronds (huttes de carton, de peaux d'animaux et de paille) sont érigés sur une terre aride aux abords d'une rivière desséchée. Des pierres aux arêtes vives jonchent le sol et rendent difficile toute circulation, à pied ou en voiture. Un vent cinglant balaie continuellement la poussière dans les yeux, les oreilles et la bouche. On a beau vaporiser des insecticides, les

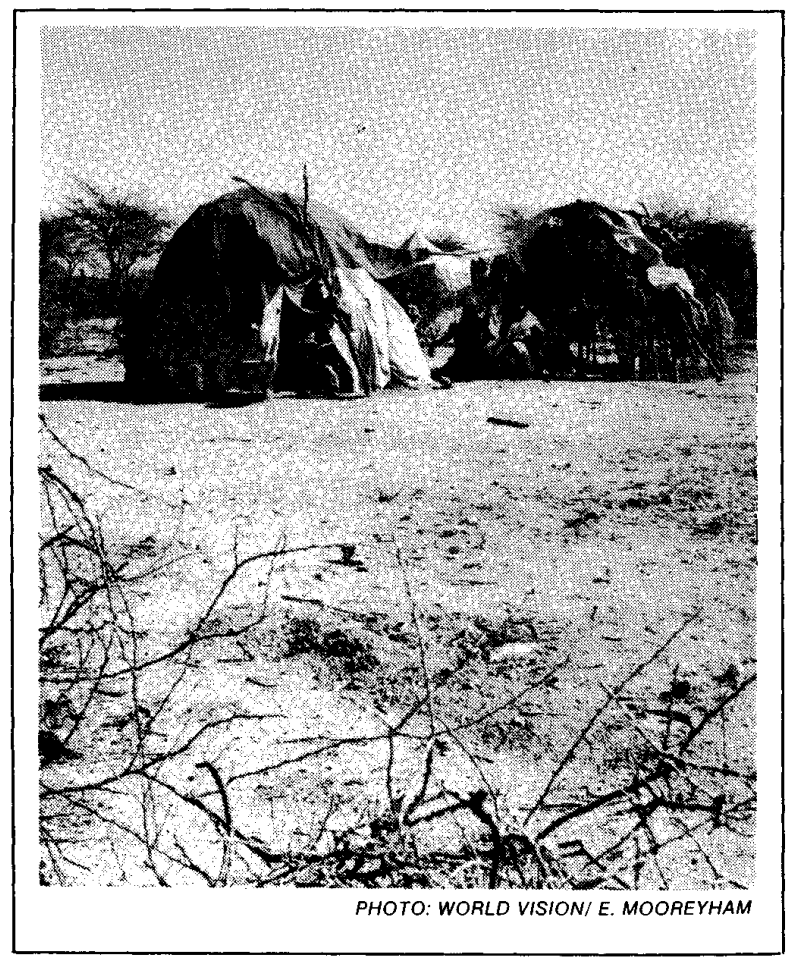

mouches bourdonnent sans arrêt autour de la figure des gens.

Les réfugiés sont à quatre-vingt-dix pour cent des femmes, des enfants, des malades et des vieillards. Nombreux sont ceux qui ont erré pendant des jours et même des semaines dans le désert impitoyable n'ayant que peu ou pas de vivres. En cours de route, ils ont été les témoins impuissants de la mort d'un grand nombre de leurs enfants. Les hommes ont été tués ou sont restés en Ogaden pour se battre ou pour protéger les quelques têtes de bétail qui restent. 
Le sort des femmes est déprimant et décourageant. Déjà minées par la malnutrition, elles doivent de leurs mains nues construire les huttes. Pour trouver des branchages, elles sont obligées de marcher toujours plus loin, parce que les terres avoisinantes ont été dénudées de leurs arbrisseaux épineux. Elles doivent creuser à la main des trous dans le lit de la rivière pour en retirer le peu d'eau qui s'y trouve. elles peuvent aussi en obtenir en allant faire la queue à l'un des huit réservoirs. J'ai vu aussi les mêmes femmes ployer sous la charge des sacs de maïs de $100 \mathrm{lb}$ reçus en ration. Le maîs est si dur qu'il faut le broyer petit à petit dans une souche évidée, à l'aide d'un bâton de bois dur de trois à quatre pieds pesant au moins dix livres, pour en obtenir une poudre utilisable. Mais le travail ne s'arrête pas là. II faut encore préparer les repas, et ces mères aux enfants très mal nourris doivent aussi passer des heures dans des centres spéciaux d'alimentation pour aider à distribuer les rations supplémentaires.

II est toujours tragique de voir des enfants malades, mais je n'oublierai jamais le regard désespéré d'une mère qui gisait sur le sol de son attel. Affligés d'une hépatite, elle était incapable de prendre soin d'ellemême ou de ses enfants. Même si je ne comprenais pas sa langue, je pouvais très bien saisir la tristesse et le désespoir qui l'accablaient.

L'équipe médicale de World Vision travaille presque sans répit pendant de longues heures dans une chaleur écrasante. Un après-midi où j'étais venu prêter main forte aux infirmières de la clinique, j'ai pu faire l'expérience des lourdes responsabilités qu'elles doivent assumer. Une jeune femme, belle et grande, nous amena son bébé de huit jours. J'avouerai sans malice, parce que c'est la vérité, que ce fragile bébé avait l'air

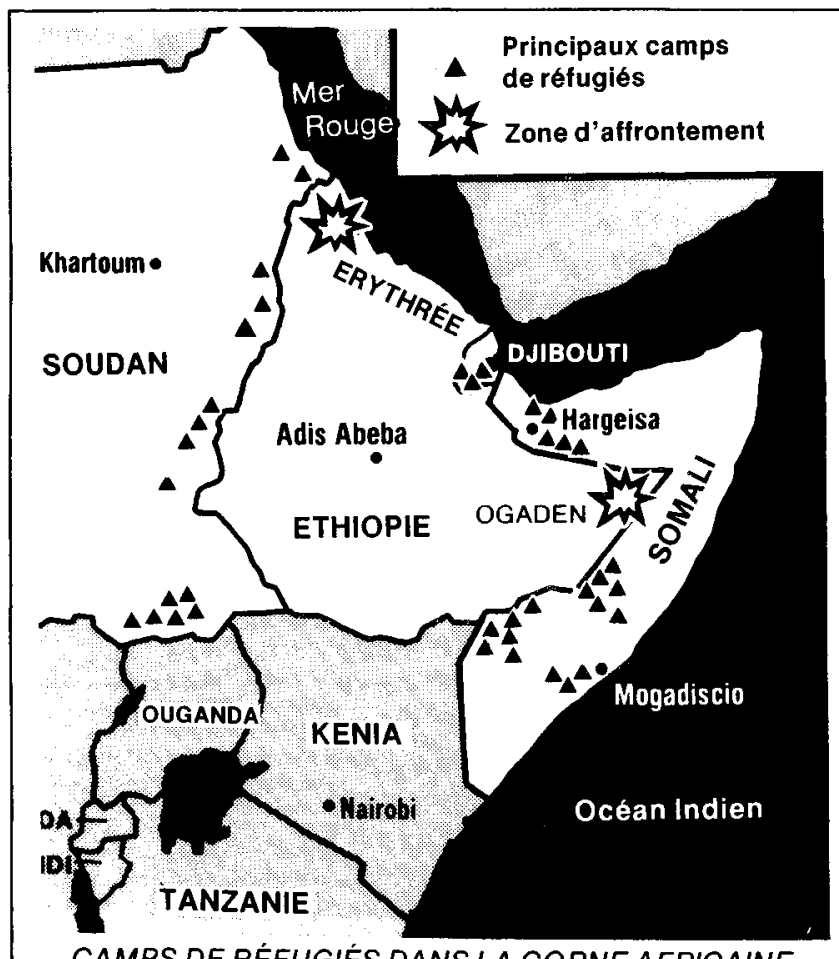

CAMPS DE RÉFUGIÉS DANS LA CORNE AFRICAINE

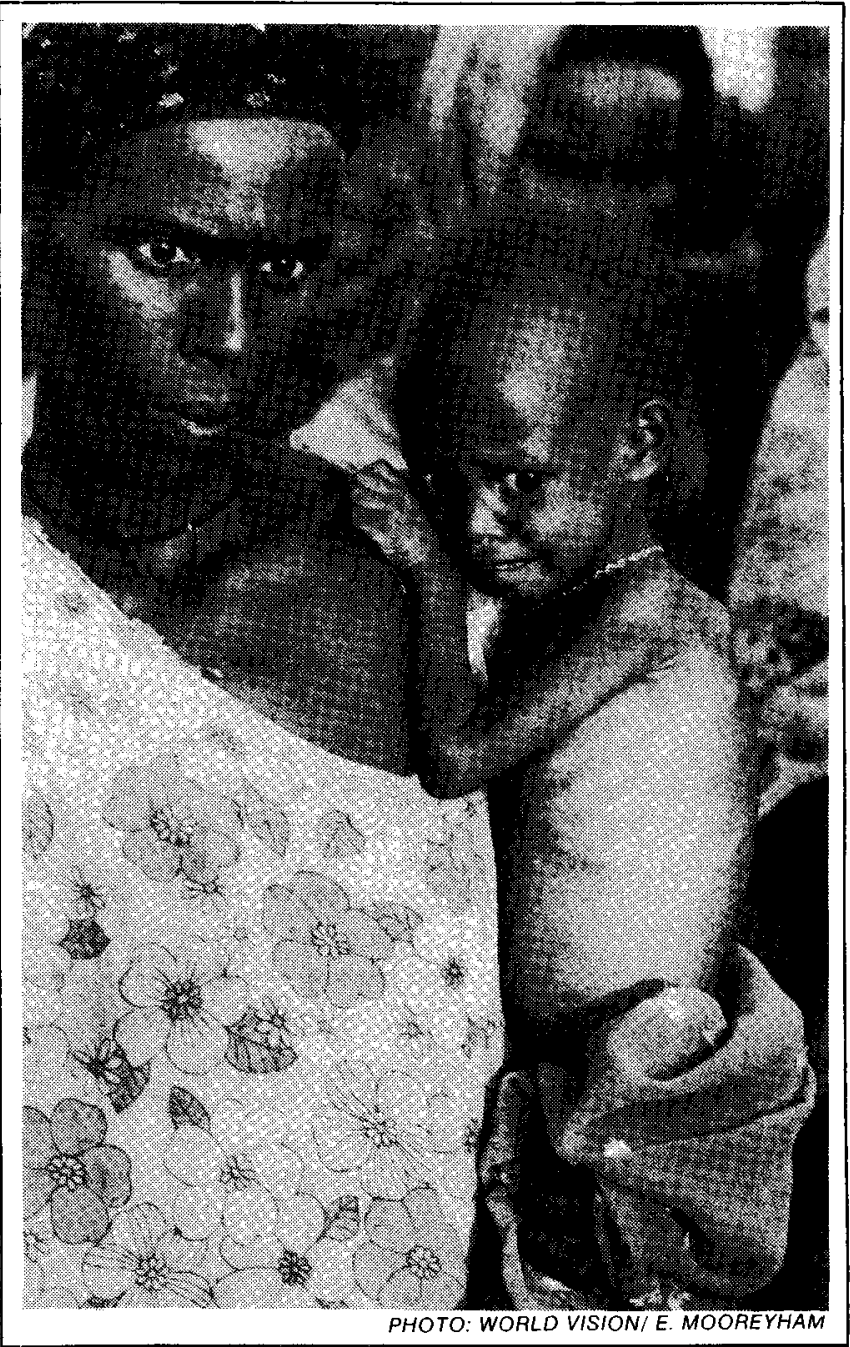

d'un vieillard d'écharné. Anne, l'infirmière, me regarda en me disant: "Elle ne survivra pas." Je ne voulais pas le croire, mais elle avait probablement raison. Anne a dû ensuite décider s'il fallait ou non lui injecter une dose de précieuse pénicilline. Devait-elle en donner à cette enfant mourante; cette seule dose suffirait-elle à la sauver? Tant d'autres ayant de meilleures chances de survie avaient aussi désespérément besoin de ce médicament.

Anne fixa cette mère dont le seul espoir dépendait de ce qu'elle pouvait faire en tant qu'infirmière. Je tins le bébé tandis qu'Anne fit une injection dans sa petite jambe desséchée. Ensemble nous avons prié Dieu de guérir cette petite.

Cétte scène se répète continuellement dans les camps de la Somalie. Souvent, les mères doivent choisir de sauver la vie d'un enfant aux dépens d'un autre. La vie est dure pour les réfugiés somaliens qui, pour la plupart, sont déchirés par le souvenir d'actes de violence, de bains de sang, de la faim et de la mort. Je n'ai pas osé les interroger sur leurs espoirs pour l'avenir. Pourtant, lorsque j'étais parmi eux, dans la puanteur, la saleté, la poussière et les insectes, ils m'accueillaient toujours avec le même mot: Nabat - la paix soit avec vous. 